\title{
Research on Reservoir Engineering Method of Well Pattern Deployment in Low-permeability Reservoirs
}

\author{
Qi Zu \\ Oil Production Company of Daqing Oilfield Company Ltd, Tenth Oil Production Plant. Daqing, \\ Heilongjiang Province, China
}

Keywords: Reservoir Engineering Method, Well Pattern Deployment, Low-permeability Reservoirs

\begin{abstract}
With the acceleration of domestic economic development, the demand for oil and energy has also been increasing. However, due to the limitation of oil extraction capacity, the contradiction between supply and demand has been continuously escalated. The reasons for limiting China's oil production capacity are not only technical but also have a close relationship with the characteristics of China's oil reservoirs. More than $60 \%$ of the proven oil reserves belong to the type of low-permeability reservoirs. This has caused certain difficulties in the oil exploitation work, and the well-planned deployment of wells is related to the success or failure of the exploitation of low-permeability reservoirs. Therefore, it is of great practical significance for the development of China's oil industry to actively carry out research on reservoir engineering methods for low-permeability reservoirs.
\end{abstract}

\section{Introduction}

The role of low-permeability oilfield development in the continued development of China's oil industry is increasingly important. Scientific research, technical research, and field testing of low-permeability oilfields have all been listed as key projects of the state and China National Petroleum Corporation. Through the research and experiments in the first two years of the "Ninth Five-Year Plan”, “Tenth Five-Year Plan” and "Eleventh Five-Year Plan”, there have been new major developments in the aspects of low-permeability oilfield feature recognition, development decision-making and process technology. However, many problems such as well pattern optimization and the development of technical policies for the development of low-permeability reservoirs such as complex fault blocks have not yet been fully resolved [1].

\section{Characteristics of Low Permeability Reservoirs}

"Low permeability" describes the reservoir's reservoir characteristics. Due to the poor permeability of the oil layer, the relative content of oil is low, and the production capacity of a single well in mining is limited. Of the total oil reserves that have been proven in China, more than $60 \%$ are low-permeability reservoirs. More complex technologies and equipment are needed in the mining process, which greatly increases the cost of utilization [2].

Low-permeability reservoirs are characterized by complex geological structures, large resistance to seepage, narrow pore throats, and poor physical properties, making them more difficult to drive than high permeability reservoirs. However, low-permeability reservoirs also have their own advantages. The most significant is the better quality of crude oil. In general, the oil reservoirs of these reservoirs are very stable in distribution, and the overall storage capacity is huge. The oil contains less water-sensitive minerals and is suitable for water injection development.

\section{Low-Permeability Reservoir Well Pattern Deployment Analysis}

China's low-permeability reservoir well pattern deployment has gone through three stages:

In the first phase, from the 1960s to the 1980s, the development well pattern of 
high-permeability reservoirs was mainly adopted. Due to the fact that China's oil extraction technology in the early days was not perfect, the equipment dedicated to the deployment of well patterns in low-permeability reservoirs was relatively lacking, so the oil production capacity at this stage was low.

In the second phase, from the 1980s to the beginning of this century, this phase began to gradually try out specialized engineering methods for low-permeability oil reservoir well pattern deployment, and optimized the injection and production well pattern and reservoir fracture system.

In the third phase, up to the present century, reservoir projects deployed in low-permeability reservoir wells have begun to take shape and have taken various forms.

In the use of low-permeability reservoirs, cracks are a special "tool". The combination of artificial fractures and natural fractures can compensate for the lack of reservoir permeability. The principle is to promote the water absorption capacity of oil reservoirs [3].

Due to the emergence of a large number of low-permeability oilfields in recent years, well network deployment studies in low-permeability reservoirs are highly valued in the industry, and this research is mainly to ensure better development of waterflooding in low-permeability reservoirs. In the author's actual investigation, it has been found that many current low-permeability oil reservoir well pattern deployment studies in China are constrained by the determination of the fracture direction, the matrix permeability, and the fracture permeability ratio, but a large number of triangular well networks and square well networks are widely used in low-permeability oil fields. The square and nine-point injection and production well network marked the remarkable results achieved by the institute in this field. For a triangular well pattern, it has the characteristics of waterline disturbance and poor post-adjustment. This feature also makes the triangular well pattern mining less effective than the square well pattern. For the square well pattern, it has wells. The flexibility of network encryption adjustment and the flexibility of injection and production well pattern conversion; and for the square anti-Nine well injection well pattern network, it is itself developed based on the square well pattern, which makes the well pattern in terms of flexibility, There are excellent performances in extending the utility, production rate, and ultimate recovery of the water-free period.

For the research on optimization of injection and production parameters in low-permeability reservoirs in recent years, the development of advanced water injection technology and the determination of reasonable bottom-hole flow pressure are all related to the research status in this field in recent years. Specifically, in the development of advanced water-flooding technology, ensuring the smooth flow of the crude oil seepage channel and maximizing the wave coefficient of the injected water are the key to this research; and for the determination of reasonable down-hole flow pressure, the use of pump efficiency The determination of reasonable bottom-hole flow pressure, the use of inflow dynamic curve equations to determine reasonable flow pressures, and the use of development experience to determine reasonable bottom-hole flow pressures are among the core elements of this study, and these will all be used for the deployment of low-permeability reservoir patterns and their injection. The study of optimization of mining parameters provides strong support [4].

In the numerical simulation study of well network deployment in low-permeability reservoirs, the author established a three-dimensional and three-phase low-permeability model in combination with a low-permeability reservoir, and finally completed a dynamic production model describing the dynamic process of reservoir development. The calculation of the index, the treatment of inclined wells, and the treatment of the layers are the key to this model. In combination with the production model of low-permeability reservoirs, the author finally found that the rectangular five-point well pattern is the best choice of well pattern in the development of low-permeability oilfields, but the application of diamond-shaped anti-non-spot well pattern will also meet the ultra-low permeability oil at most times. Tibetan development needs. In the study of the optimization of well spacing and row spacing, the authors found that large well spacing is not better than low-permeability reservoirs with small well spacing. When the well spacing is fixed, the row spacing can be reduced to a certain extent to ensure low-permeability oil. The increasingly 
homogeneous distribution of reservoirs naturally leads to a better realization of the exploitation of low-permeability reservoirs. It is worth noting that the low-permeability reservoir study object selected by the author has determined that the $360 \times 150$ rectangular five-well pattern is the best form of deployment, and this form is similar to the $380 \times 150$ rectangular five-point well network currently used in the reservoir. There is not much difference between them, so you can enjoy the value of this link in a certain degree.

Conventional low-permeability oilfield well pattern: Most conventional low-permeability oilfields use area water injection. Area water injection methods the well layouts centered on oil wells include four-point method, five-point method, seven-point method, nine-point method, linear determinant method, and honeycomb system. If the injection well is the center, it is called anti-inversion. Some points. According to the theoretical analysis, when the water-absorbing capacity of an oilfield injection well is particularly high, an area well pattern with a low water injection intensity should be used, such as a four-point method or an inverse nine-point method; when the water absorption capacity is particularly low, an injection well pattern with a large water injection intensity should be used. For example, the seven-point method or the nine-point method; generally, the five-point method is considered to be a reasonable and superior area of water injection. A large number of oilfield practices showed that in the initial stage of oilfield development, the area injection method using the square well pattern against the nine-point method was indeed more flexible and superior. For other areas of water injection wells, such as the triangle's four-point method, after the injection and production system is certain, there is basically no room for adjustment. For fault block oil fields or oil fields with small oil areas, the development well pattern should be deployed and adjusted according to the geometry of the reservoir and the oil-bearing area, not necessarily in accordance with the regular well pattern and injection and production system.

\section{Influencing Factors of Well Pattern Deployment in Low Permeability Reservoirs}

The study of reservoir engineering methods for the deployment of low-permeability oil reservoir well patterns is essentially a rational approach to achieve the highest mining yields on the premise of less cost investment. One of the most important factors is the density configuration of well pattern in low-permeability reservoirs. If the density is too large, the economic cost of the input will inevitably be too high; if the density is too small, the production capacity cannot be fully realized. Therefore, the optimization is to set the well pattern density of the reservoir within a reasonable range.

Based on the analysis of the status quo, there are five main factors affecting the well density of low permeability reservoirs.

The characteristics of low-permeability oil reservoirs are not high. Water flooding is a commonly used method. Because the continuity of oil sands in low-permeability reservoirs is poor and the distribution range is very small, the well spacing in the process of constructing the oil well pattern network is smaller than that of the general oil reservoir area, so that the oil layers at different heights can be connected. In order to obtain better oil production, it is necessary to increase the control granularity of water-flooding, that is, the proportion of the total reserves in the area covered by water-flood increases [5].

It is very important to measure the production of low-permeability reservoirs. In a fixed area, there is a close relationship between reservoir output and well pattern density. If the relationship between quantity and production curve is judged, the range of well spacing is reasonable. The two sides are in a positive proportion relationship, that is, the greater the well density, the greater the reservoir production. Reservoir production estimation is based on petroleum surveying technology. This data has important guiding significance for low-permeability reservoir areas.

Many of China's low-permeability oilfields have entered the secondary or tertiary oil recovery stage after long-term exploitation. A large number of practices have proved that, with the extension of mining time, low-permeability oilfields need to increase the wellbore density and shorten the well spacing. Distance, this phenomenon is also referred to as "continuous oil production 
investment"; and the crude oil collection and production ratio refers to the period when well pattern density is continuously invested and recovered.

Many low-permeability oilfields discovered during the mining process that increasing well pattern density has had an impact on recovery, thus forming the erroneous view that "as long as the wells are increased, they can continue to increase production capacity". It can only be said that increasing the net density in a proper range can increase the crude oil extraction rate. Once the reasonable limit is exceeded, the actual economic benefits begin to shrink.

Compared with high-permeability reservoirs, the production rate of low-permeability reservoirs is obviously insufficient, and the use of appropriate adjustments to the well density can be used to make up for this. Crude oil is mainly exposed to the sandstone layer. Sandstone layers in low-permeability reservoirs are more harmful during oil recovery. If long-term production naturally leads to a decrease in productivity, proper layout of well pattern density is to be improved in the shortest possible time.

\section{Conclusion}

China's natural world has less oil reserves and insufficient production capacity, which greatly limits the application of petroleum energy. Actively carrying out research on well network deployment in low-permeability reservoirs can turn unfavorable factors into effective production capacity and make up for market supply and demand inconsistencies. From the technical point of view, in order to obtain better results in the exploitation of low-permeability reservoirs, it is necessary to strengthen the control of water injection and flooding technologies, and the general control level is over $70 \%$. At the same time, taking into account the poor precipitation conditions and poor physical properties of low-permeability reservoirs, these have brought troubles to well network deployment; combined with the rational use of artificial cracks and natural cracks, can improve the oil displacement effect and reduce the cost.

\section{References}

[1] Wang Y. Study on well spacing and effective use of low-permeability reservoirs[D]. Chengdu: Southwest Petroleum University, 2011.

[2] Zhong Pingping, Peng Caizhen. Review of calculation methods for well pattern density in reservoir[J]. Petroleum Geology and Engineering,2009,2(23):60-63.

[3] Zhai Ke. Study on Rational Well Density in Low Permeability Reservoirs[D]. Chengdu: Southwest Petroleum University, 2006.

[4] Wang Jingyao, Ma Desheng, Li Jun, et al. Adaptability Analysis of Well Patterns for Advanced Waterflooding in Low Permeability Reservoirs[J]. Journal of Southwest Petroleum University, 2011, 2(33): 125-128.

[5] Jiang Ming. Research on well network adaptability of Erlian low-permeability sandstone reservoir[J]. Special Oil and Gas Reservoirs, 2000,1(7):20-22. 